\title{
Nephrology
}

\section{Chemokine Receptor CCR1: A New Target for Progressive Kidney Disease}

\author{
Volha Ninichuk Hans-Joachim Anders \\ Nephrological Center, Medical Policlinic, Ludwig Maximilians University of Munich, Munich, Germany
}

\section{Key Words}

Chemokines $\cdot$ Inflammation $\cdot$ Kidney disease $\cdot$ Fibrosis

\begin{abstract}
Infiltrating leukocytes are thought to contribute to the progression of kidney disease. Locally produced chemokines guide circulating leukocytes into the kidney, which renders therapeutic blockade of respective chemokine receptors on the leukocyte surface as potential targets for the inhibition of renal leukocyte recruitment. By using mutant mice and specific antagonists, we found that chemokine receptor CCR1 has non-redundant functions for leukocyte adhesion to activated vascular endothelium and for transendothelial diapedesis. Most importantly, CCR1 blockade with a specific small molecule antagonist can improve injury in several types of progressive kidney disease models, even if treatment is initiated in advanced disease states. Identification of new targets may add to the therapeutic options in chronic kidney disease.
\end{abstract}

Copyright $(2005$ S. Karger AG, Basel

\section{Introduction}

The global burden of chronic kidney diseases remains an ongoing medical challenge. Therapies that can halt or reverse advanced renal injury are not available. Increasing numbers of patients progress to end-stage renal failure and require renal replacement therapy, the latter being associated with significant mortality, a lower quality of life, and high costs for national health systems. Thus, new treatment strategies that slow down, halt or even revert progressive renal damage are requested. Current treatments for chronic renal failure target to correct renal hemodynamics, proteinuria, high blood pressure, hyperparathyroidism or to avoid nephrotoxic drugs and nicotine abuse. A general role of immunosuppressive drugs in chronic kidney disease is not established, because of lack of efficacy or unacceptable side effects of systemic immunosuppression.

Many types of chronic kidney diseases are characterized by an accumulation of interstitial leukocytes. Infiltrating leukocytes are a major source for proinflammatory and profibrotic cytokines and are therefore critical for mediating fibroblast proliferation, differentiation into myofibroblasts, matrix production, and tubular atrophy [1]. Thus, interfering with renal leukocyte recruitment may represent a valuable strategy to reduce renal inflammation, tissue remodeling, and progressive loss of renal function. During the past decade we and others have unraveled the role of chemokines and chemokine receptors that direct circulating leukocytes into the damaged kidney, which was recently reviewed in detail [2]. In this article, we focus on chemokine receptor CCR1 that was identified from a group of other chemokines to play a critical role for interstitial leukocyte recruitment.

\section{KARGER \\ Fax +4161306 1234 E-Mail karger@karger.ch} www.karger.com
C 2005 S. Karger AG, Basel 0250-8095/05/0254-0365\$22.00/0

Accessible online at: www.karger.com/ajn
H.-J. Anders, MD

Medizinische Poliklinik der LMU

Pettenkoferstrasse 8a, DE-80336 Munich (Deutschland)

Tel. +49 89218075846, Fax +49 89218075860

E-Mail hjanders@med.uni-muenchen.de 
Table 1. Classification of chemokines and chemokine receptors

\begin{tabular}{llllll}
\hline Ligand & & Receptors & Ligand & & Receptors \\
\hline CXCL1 & Gro $\alpha$ & CXCR1,2 & CCL1 & I-309 & CCR8 \\
CXCL2 & Gro $\beta$ & & CCL2 & MCP-1 & CCR2 \\
CXCL3 & Groy & & CCL3 & MIP-1 $\alpha$ & CCR1, 5 \\
CXCL4 & PF4 & CXCR1, 2 & CCL4 & MIP-1 $\beta$ & CCR5 \\
CXCL5 & ENA-78 & CXCR2 & CCL5 & RANTES & CCR1, 3, 5 \\
CXCL6 & GCP-2 & CXCR1, & CCL7 & MCP-3 & CCR1, 2 \\
CXCL7 & NAP-2 & CXCR2 & CCL8 & MCP-2 & CCR1, 2, \\
CXCL8 & IL-8 & CXCR1,2 & CCL11 & Eotaxin & CCR3 \\
CXCL9 & Mig & CXCR3 & CCL13 & MCP-4 & CCR1, 2, 3 \\
CXCL10 & IP-10 & CXCR3 & CCL14 & HCC-1 & CCR1 \\
CXCL11 & I-TAC & CXCR3 & CCL15 & HCC-2 & CCR1 \\
CXCL12 & SDF-1 & CXCR4 & CCL16 & HCC-4 & CCR1, 8 \\
CXCL13 & BCA-1 & CXCR5 & CCL17 & TARC & CCR4 \\
CXCL14 & Bolekine & & CCL18 & DC-CK1 & \\
CXCL15 & Lungkine & & CCL19 & ELC & CCR7 \\
& & & CCL20 & LARC & CCR6 \\
\hline XCL & & & CCL21 & SLC/6Ckine & CCR7 \\
XCL1 & Lymphotactin & XCR1 & CCL22 & MDC & CCR4 \\
XCL2 & SCM-1 $\beta$ & & CCL23 & MPIF-1 & CCR1 \\
& & & CCL24 & Eotaxin-2 & CCR3 \\
& & & CCL25 & TECK & CCR9 \\
\hline CX3CL & & & CCL26 & Eotaxin-3 & CCR3 \\
CX3CL1 & Fractalkine & CX3CR1 & CCL27 & CTAK/Eskine & CCR10 \\
\hline
\end{tabular}

\section{Chemokines and Chemokine Receptors in Renal Leukocyte Recruitment}

\section{Chemokines and Chemokine Receptors}

Chemokines are a large family of low molecular weight cytokines that cause migration of leukocytes. The nomenclature used to describe individual chemokine ligands is based upon the four-cysteine motif in their amino acid sequence as listed in table 1 [3]. Chemokines can be further classified according to their predominant function and expression pattern. For example, chemokines such as CCL21 or CCL19 are classified as homeostatic chemokines. They are involved in physiological homing of leukocytes to lymphoid tissues [4, 5], and in lymphocyte and dendritic cell trafficking during immune surveillance [6]. Chemokines such as CCL2, CCL3, CCL5, and CXCL10 are classified as proinflammatory chemokines because they mediate the recruitment of leukocytes to sites of tissue injury $[7,8]$. Chemokines can interact with only one receptor or a single chemokine binds to multiple receptors [8].

Chemokines mediate their biologic actions through a family of more than 20 seven-transmembrane-spanning G-protein-coupled receptors $[4,9,10]$. Chemokine recep- tors are designated according to the class of their chemokine ligands, e.g. CR, CCR, CXCR, and CX3CR (table 1). Chemokine receptors show restricted expression on subclasses of leukocytes. Because the ligand specificities of the receptors can substantially overlap within a chemokine class, a high degree of redundancy of single chemokines was suspected $[5,8]$. In general, the proinflammatory chemokine receptors have promiscuous ligand binding specificities. This finding gave rise to the concept that blocking chemokine receptors could represent a rational approach to target the chemokine system rather than targeting a single chemokine.

\section{Chemokines and Chemokine Receptors Mediate \\ Leukocyte-Endothelial Cell Interactions}

Chemokines are involved in the interactions of leukocytes and activated endothelial cells at multiple stages [5, 11]. Injured renal cells produce inflammatory mediators that enhance the expression of adhesion molecules on endothelial cells of capillaries adjacent to the inflammatory lesion. Selectins mediate the rolling process of leukocytes along the endothelial surface and thereby allow contact of leukocytes with chemokines. The Duffy antigen receptor for chemokines (DARC) can bind chemokines 
at post-capillary venules [12]. However, in various forms of renal diseases, DARC expression expands to peritubular vessel endothelium and thereby marks specific exit sites for leukocytes into the renal interstitium [12]. Chemokines ligate their respective receptors on the surface of the rolling leukocyte. This activates leukocyte-expressed $\beta_{2}$-integrins, resulting in firm adhesion of the leukocyte to the endothelial surface as a prerequisite for leukocyte transmigration $[5,7,13]$. Other chemokine receptors appear to differentially influence spreading, diapedesis, and subsequent migration into the tissue space $[5,14]$. For example, monocytes and T cells express both chemokine receptors CCR 1 and CCR5 [15]. In an in vitro system it was found that immobilized CCL5 induced leukocyte arrest via CCR1, while leukocyte spreading was mediated via CCR5, and transendothelial migration was supported by both receptors [15]. In this context it is of interest that chemokines also modulate the redistribution of junctional adhesion molecules at endothelial cell tight junctions that may promote leukocyte diapedesis by transient opening of focal cell-cell contacts [16]. Furthermore, CCL5 up-regulates the secretion and activity of matrix metalloproteinases by infiltrating leukocytes [17], thus facilitating leukocyte transmigration through the basement membrane and extracellular matrix [18].

\section{Chemokines and Chemokine Receptors in Renal Inflammation}

All types of renal cells can produce chemokines upon stimulation [reviewed in 11]. Proinflammatory stimuli including reactive oxygen species, growth factors and vasoactive agents like angiotensin II can stimulate chemokine production of renal cells. Furthermore, immune complexes and complement activation cause mesangial production of chemokines. In proximal tubular cells, chemokines can be induced by LPS [19], high concentrations of albumin $[20,21]$ or exposure to both calcium oxalate and calcium phosphate crystals [22]. Besides intrinsic renal cells, infiltrating leukocytes are a major source of local chemokine production in a positive amplification loop $[23,24]$, as chemokines secreted by infiltrating leukocytes promote additional leukocyte recruitment [25]. It is important to note that chemokine expression is restricted to the injured compartment of the kidney [reviewed in 26]. The spatial expression of chemokines in the kidney correlates with the local accumulation of inflammatory cell infiltrates and renal damage $[2,24]$. Data from animal models have been confirmed by human renal biopsy studies [12, 27-29].

CCR1 in Progressive Kidney Disease
Termination of the trigger injury correlates with a reduction of chemokine expression by intrinsic renal cells and infiltrating leukocytes [30]. As further influx of leukocytes does not occur, the number of infiltrating leukocytes declines in parallel to the resolution of disease. It is important to note that termination of the chemokine signal is critical for the resolution of the inflammatory process. If local chemokine expression is augmented by another trigger of chemokine release, a pre-existing renal disease may eventually progress to severe renal damage. For example, intercurrent infections frequently result in a deterioration of renal diseases including chronic transplant nephropathy. The proinflammatory signals of bacterial and viral invasion are mediated by Toll-like receptors (TLRs) [31]. TLRs recognize pathogen-associated molecules such as LPS, peptidoglycanes, and unmethylated CpG-DNA [31]. We recently found that injection of unmethylated $\mathrm{CpG}$-DNA into mice with otherwise selflimiting immune complex glomerulonephritis resulted in progression instead of resolution of the disease process. This was associated with increased chemokine expression and subsequent glomerular macrophage recruitment [32]. Even if the triggering injury subsides, renal chemokine expression can be maintained by other mechanisms such as infection, renin-angiotensin activation, hypoxia or proteinuria, and contribute to persistent leukocyte infiltration and tissue damage. Many studies addressed the functional role of single chemokines or chemokine receptors in defined renal disease models by applying either neutralizing antibodies, DNA vaccination, chemokine receptor antagonists, or by using mutant mice [reviewed in 24]. Among those, only a few studies have administered specific antagonists late in the disease process, which most appropriately mimics treatment of established kidney disease. Such data is only available for specific blockade of CCR1.

\section{Identifying CCR1 as a Target}

Human CCR1 binds several CC chemokines, including CCL3 (table 1). The amino acid sequence of human CCR1 has a high degree of homology to murine CCR1 (fig. 1). However, species-specific pharmacodynamics need to be defined for each antagonist when to be tested in another species [33]. The latter often compromises the interpretation of data generated in rodents that apply chemokine antagonists designed for the human system. CCR1 is expressed at low levels on T cells. By contrast, human and murine blood monocytes, tissue macrophages, neutrophils, and eosinophils express CCR 1 at high levels $[3,29,34]$. Upon ligation with its ligands, a conforma- 
Fig. 1. Alignment of human and mouse CCR1. Known or predicted helixes are highlighted in light gray. Known or predicted $\beta$-strands are highlighted in dark gray. Cysteine residues are encircled. Disulfide bonds is indicated by the letter ' $\mathrm{S}$ '.
hCCR1 METPNTTEDYDTTTEFDYGDATPCQKVNERAFGAQLLPPLYSLVFVIGLVGNI LVVLVL mCCR1 MEI SDFTEAYP TTTEFDYGDSTPCQKTAVRAFGAGLLPPLYSLVF I IGVVGNVLVILVL

hCCR1 VQYKRLKNMTSIYLLNLAI SDLLFLFTLPFWIDY.KLKDDWVFGDAM CKILSGFYYT.GL mCCR1 MQHRRLQSMTSIYLFNLAVSDVLFLFTLPFWIDY.KLKDDWI FGDAMC KILSGFYYL.GL

hCCR1 YSEIFFIILLZIDRYLAIVHAVFALRARTVTFGVITSIIIWALAILASMPGLY.FSKTQWEFT mCCR1 YSEIFFIILLZIDRYLAIVHAVFALRARTVTFGIITSIITWALAILASMPALY. FFKAQWEFT

hCCR1 HHT किLHFPHESLREWKLFQALKLNLFGLVLPLLVMI OYTGIIKILLRRPN ......... mCCR1 HRT]CPHFPYKSLKQWKRFQALKLNLLGLILPLLVMICYAGIIRILLRRPS .........

hCCR1 EKKS KAVRLIFVIMI IFFLFWTPYNLTI LI SVFQDFLFTHECEQS RHLDLAVQVTEVIA MCCR1 EKKVKAVRLIFAITLLFFLLWTPYNLSVFVSAFQDVLFTNQCEQSKQLDLAMQVTEVIA

hCCR1 YTHCCVNPVIYAFVGERFRKYLRQLFHRRVAVHLVKWLPFLSVDRLERVSSTSPSTGEH MCCR1 YTHCCVNPI IYVFVGERFWKYLRQLFQRHVAI PLAKWLPFLSVDQLERTSS ISPSTGEH

hCCR1 ELSAGF

hCCR1 ELSAGF tional change of the seven-transmembrane elements of CCR1 leads to intracellular activation of G-protein subunits. Studies using an in vitro flow chamber system first identified a critical role for CCR1 for adhesion of rolling macrophages or $\mathrm{T}$ cells to activated endothelium using established human cell lines [15]. These findings were validated in vivo by two approaches. First, we used intravital microscopy of the cremaster muscle in mice to study the role of CCR1 for leukocyte rolling, firm adhesion, transendothelial migration, and interstitial migration. Either by applying a specific CCR1 antagonist or performing intravital microcopy in CCR1-deficient mice, we found that CCR1 is required for leukocyte adhesion and transendothelial migration during the recruitment process [35]. The coherent findings in antagonist-treated mice or CCR1-deficient mice argue for a non-redundant role of CCR1 in that processes. Because organ-specific roles of chemokines and chemokine receptors have been reported, studies performed on cremaster muscles do not allow a conclusion upon the role of CCR 1 in the kidney. Thus, as a second approach we isolated macrophages and $\mathrm{T}$ cells from spleens of CCR1-deficient or wild-type mice.
After ex vivo labeling with a fluorescence dye, cells were injected into mice with renal fibrosis after unilateral ureteral obstruction (UUO) [36]. CCR1-deficient macrophages and T cells showed markedly reduced recruitment to the interstitial compartment of diseased kidneys as compared to cells isolated from wild-type mice [36]. These data show that CCR 1 on macrophages and T cells is required for interstitial leukocyte recruitment in renal fibrosis in mice.

\section{Compartment-Specific Role of CCR1}

Human renal biopsy studies have localized renal CCR 1 expression to macrophages in glomerular and interstitial inflammatory cell infiltrates in several types of kidney disease [29]. However, the presence of a receptor found on cells that infiltrate the kidney does not necessarily provide evidence for its functional role in the recruitment process. In fact, organ- and even compartment-specific roles of chemokine receptors may occur. When we treated autoimmune MRL ${ }^{l p r / l p r}$ mice with lupus nephritis with BX471, a small molecule CCR1 antagonist, we noted that despite a marked reduction of interstitial leukocyte 
counts, the number of glomerular macrophages was not affected compared to vehicle-treated MRL ${ }^{l p r / p r}$ mice [37]. Cell transfer studies with labeled leukocytes revealed that CCR 1, while critical for interstitial leukocyte recruitment, is not required for their recruitment into the glomerular compartment of nephritic MRL ${ }^{l p r / p r}$ mice. We obtained similar results in BALB/c and BKS mice with glomerular pathology. By contrast, we could show that CCR5 mediates glomerular but not interstitial macrophage recruitment $[23,36]$. Given the fact that CCR 1 and CCR 5 are present on circulating monocytes and T cells, other factors appear to determine their selective roles for recruitment in different microvascular beds. The interaction of chemokines with their receptors requires additional molecules, e.g. respective binding sites on endothelial cell proteoglycans or DARC that expose the chemokine to the luminal endothelial cell membrane. If endothelial cells of glomerular or peritubular capillaries expose different chemokines in mice, and if these observations hold true for the human kidney, remains a future goal of our ongoing research activities in this field.

\section{Late Onset CCR1 Antagonism with a Small Molecule CCR1 Blocker in Models of Progressive Kidney Disease}

\section{Acute and Chronic Renal Allograft Rejection}

The first study that used the small molecule CCR1 antagonist BX471 in kidney disease was reported by Horuk et al. [38] in 2001. In this study, BX471 monotherapy had beneficial effects on serum creatinine levels and renal survival in a model of kidney transplantation in rabbits. Pathologic analysis showed that BX471 was similar to cyclosporine in its ability to prevent extensive infarction of transplanted kidneys [38]. Furthermore, BX471 prevented chronic allograft nephropathy in a Fischer 344 into Lewis rat model of acute and chronic allograft rejection [39]. BX471 given from day 21 to 42 after kidney transplantation reduced the number of ED-1-positive macrophages in renal allografts in association with a reduction of markers of renal fibrosis.

\section{Obstructive Nephropathy}

Experimental UUO represents a model for obstructive nephropathy but also allows insight into the process of interstitial fibrosis that is a common characteristic of many chronic nephropathies. UUO kidneys show increased CCR1 expression as compared to their respective non-obstructed contralateral kidneys [40]. UUO kidneys from mice treated with the CCR 1 antagonist BX471 revealed a marked reduction of interstitial leukocyte counts [41]. Markers of renal fibrosis, such as interstitial fibroblasts, interstitial volume, mRNA and protein expression for collagen I, were all significantly reduced by BX471 compared to vehicle-treated controls. Most interestingly, the beneficial effect was comparable when BX471 was given not before day 6 , indicating that late onset of CCR1 blockade may still be effective. By contrast, treatment was ineffective when the drug was supplied only from day 0 to day 5 . These data were confirmed by inducing UUO in CCR1-deficient mice [36]. Thus, we decided to further evaluate CCR 1 as a potential target for reducing interstitial leukocyte recruitment and fibrosis as major factors for the process of progression to end-stage renal failure.

\section{Immune Complex Glomerulonephritis}

Chemokines are also involved in systemic immune responses [3], so that data from the UUO model may not apply to renal manifestations of systemic autoimmunity, e.g. lupus nephritis. In fact, lack of CCR1 has been reported to be associated with an enhanced Th1-like immune response and aggravation of nephrotoxic serum nephritis [42]. We therefore studied the effects of therapeutic CCR1 blockade in progressive lupus-like immune complex glomerulonephritis of MRL ${ }^{l p r / p r}$ mice. BX471 treatment initiated late during the course of disease (weeks 20-24 of age) improved blood urea nitrogen levels and reduced the amount of macrophages and lymphocytes in the interstitium [37]. Furthermore, BX471 reduced the extent of interstitial fibrosis as evaluated by interstitial smooth muscle actin expression and collagen I deposits, as well as mRNA expression for collagen I and TGF- $\beta_{1}$. BX471 did not affect serum DNA autoantibodies despite potential roles of $\mathrm{CC}$ chemokines and their receptors in systemic immune responses. As CCR 1 blockade does not reduce glomerular macrophage recruitment, it was found to be ineffective in modulating glomerular pathology and proteinuria in $\mathrm{MRL}^{l p r / l p r}$ mice.

\section{Focal Segmental Glomerulosclerosis}

Proteinuria represents a major prognostic factor for the progression of renal disease, because unselective proteinuria can induce chemokine expression in renal tubular cells [43]. Thereby proteinuria serves as a major factor for tubulointerstitial inflammation. Thus, we questioned whether CCR 1 antagonism would be able to improve interstitial fibrosis in the presence of massive proteinuria caused by focal segmental glomerulosclerosis (FSGS). 
FSGS was induced in BALB/c mice by two intravenous injections of adriamycin at day 0 and 14 . BX471 was started from day 14 when nephrotic syndrome was established. Again, BX471 reduced the amount of interstitial macrophages and $\mathrm{T}$ cells and markers of renal fibrosis including interstitial fibroblasts and interstitial volume [44]. These findings demonstrate that therapeutic CCR 1 blockade is effective in the presence of heavy proteinuria. Consistent with our previous findings, BX471 did not affect glomerular pathology in adriamycin-injected $\mathrm{BALB} / \mathrm{c}$ mice.

\section{Glomerulosclerosis in Alport Nephropathy}

Alport syndrome is a common type of hereditary glomerulopathy leading to glomerulosclerosis with subsequent interstitial fibrosis progressing to end-stage renal disease. Disease progression has been thought to be mediated mostly by non-inflammatory factors, but recent studies have documented the role of interstitial macrophages for tubular atrophy in collagen4A3-/- mice, with renal lesions comparable to humans [45]. We treated collagen4A3-/- mice with BX471 or vehicle beginning from 6 weeks of age for 4 weeks [35]. Vehicle-treated collagen4A3-/- mice showed a mean survival of 69 days (95\% confidence interval, 64-74 days), whereas daily treatment with BX471 from week 6 increased mean survival to 86 days ( $95 \%$ confidence interval, $80-92$ days; $\mathrm{p}=0.0002)$. BX471 treatment was associated with less interstitial macrophages, apoptotic tubular epithelial cells, tubular atrophy, interstitial fibrosis, and less globally sclerotic glomeruli as compared to vehicle-treated mice. In contrast, BX471-treated collagen4A3-/- mice showed a higher density of peritubular capillaries. Obviously, blocking CCR1-mediated interstitial macrophage recruitment can maintain peritubular microvasculature and prevent tubular atrophy, two major factors for disease progression in inflammatory and non-inflammatory types of progressive nephropathies. These data also indicate the crucial role of macrophage infiltrates for the progression of chronic kidney disease.

\section{Diabetic Nephropathy}

Diabetic nephropathy is the most common type of chronic kidney disease progressing to renal failure. Available rodent models of diabetic nephropathy are frequently used to study the early glomerular changes of diabetic nephropathy [46]. However, rodents usually do not develop advanced interstitial lesions as they occur in late stages of human diabetic nephropathy [47]. Recently, Chow et al. [48] reported that $\mathrm{db} / \mathrm{db}$ mice develop sig- nificant interstitial macrophage infiltrates at 6 months of age. We injected male $\mathrm{db} / \mathrm{db}$ mice from 5 months of age for 10 days and obtained renal tissue for histopathological analysis. BX471 reduced the number of macrophages in the renal interstitium as compared to vehicle-treated $\mathrm{db} / \mathrm{db}$ mice [unpubl. observation], supporting the hypothesis that blocking interstitial macrophage recruitment with CCR1 antagonists may be beneficial also in diabetic nephropathy.

In summary, CCR 1 blockade can effectively prevent recruitment of monocytes and lymphocytes into the renal interstitium. BX471 is effective in multiple models of progressive kidney disease in mice even when treatment was started late in the disease process. Thus, interfering with renal leukocyte recruitment by targeting CCR 1 may represent a promising strategy to prevent disease progression in chronic nephropathies characterized by interstitial leukocytic cell infiltrates.

\section{Acknowledgments}

This work was supported by grants from the German Kidney Foundation, the Wilhelm Sander Foundation and the Else-Kröner Fresenius Foundation. V.N. and H.J.A. were also supported by the EU Network-of-Excellence 'MAIN'. 


\section{References}

1 Eddy AA: Molecular basis of renal fibrosis. Pediatr Nephrol 2000;15:290-301.

2 Anders HJ, Vielhauer V, Schlöndorff D: Chemokines and chemokine receptors are involved in the resolution or progression of renal disease. Kidney Int 2003;63:401-415.

3 Zlotnik A, Yoshie O: Chemokines: a new classification system and their role in immunity. Immunity 2000;12:121-127.

4 Murphy PM, Baggiolini M, Charo IF, Hebert CA, Horuk R, Matsushima K, Miller LH, Oppenheim JJ, Power CA: International Union of Pharmacology. XXII. Nomenclature for chemokine receptors. Pharmacol Rev 2000;52: 145-176.

5 Nelson PJ, Krensky AM: Chemokines, chemokine receptors, and allograft rejection. Immunity $2001 ; 14: 377-386$.

6 Moser B, Loetscher P: Lymphocyte traffic control by chemokines. Nat Immunol 2001;2: 123-128.

7 Luster AD: Chemokines - chemotactic cytokines that mediate inflammation. $\mathrm{N}$ Engl $\mathrm{J}$ Med 1998;338:436-445.

8 Baggiolini M: Chemokines and leukocyte traffic. Nature 1998;392:565-568.

9 Rossi D, Zlotnik A: The biology of chemokines and their receptors. Annu Rev Immunol 2000; 18:217-242.

10 Sallusto F, MacKay CR, Lanzavecchia A: The role of chemokine receptors in primary, effector and memory immune responses. Annu Rev Immunol 2000;18:593-620.

11 Segerer S, Nelson PJ, Schlöndorff D: Chemokines, chemokine receptors, and renal disease: from basic science to pathophysiologic and therapeutic studies. J Am Soc Nephrol 2000; 11:152-176.

12 Segerer S, Regele H, Mack M, Kain R, Cartron JP, Colin Y, Kerjaschki D, Schlondorff D: The Duffy antigen receptor for chemokines is upregulated during acute renal transplant rejection and crescentic glomerulonephritis. Kidney Int 2000;58:1546-1556.

13 Tanaka Y, Adams DH, Hubscher S, Hirano H, Siebenlist U, Shaw S: T-cell adhesion induced by proteoglycan-immobilized cytokine MIP1ß. Nature 1993;361:79-82.

14 Weber KS, von Hundelshausen P, Clark-Lewis I, Weber PC, Weber C: Differential immobilization and hierarchical involvement of chemokines in monocyte arrest and transmigration on inflamed endothelium in shear flow. Eur $\mathbf{J}$ Immunol 1999;29:700-712.

15 Weber C, Weber KS, Klier C, Gu S, Wank R, Horuk R, Nelson PJ: Specialized roles of the chemokine receptors CCR1 and CCR5 in the recruitment of monocytes and Th1-like/ $\mathrm{CD} 4 \mathrm{RO}^{+} \mathrm{T}$ cells. Blood 2001;97:11441146.

16 Ostermann G, Weber KS, Zernecke A, Schroder A, Weber C: JAM-1 is a ligand of the $\beta_{2}$ integrin LFA-1 involved in transendothelial migration of leukocytes. Nat Immunol 2002;3: $151-158$.
17 Klier CM, Nelson EL, Cohen CD, Horuk R, Schlondorff D, Nelson PJ: Chemokine-induced secretion of gelatinase B in primary human monocytes. Biol Chem 2001;382:14051410.

18 Leppert D, Waubant E, Galardy R, Bunnett NW, Hauser SL: T cell gelatinases mediate basement membrane transmigration in vitro. J Immunol 1995;154:4379-4389.

19 Tsuboi N, Yoshikai Y, Matsuo S, Kikuchi T, Iwami K, Nagai Y, Takeuchi O, Akira S, Matsuguchi T: Roles of toll-like receptors in C-C chemokine production by renal tubular epithelial cells. J Immunol 2002;169:20262033.

20 Wang Y, Rangan GK, Tay YC, Wang Y, Harris DC: Induction of monocyte chemoattractant protein- 1 by albumin is mediated by nuclear factor- $\kappa \mathrm{B}$ in proximal tubule cells. J Am Soc Nephrol 1999;10:1204-1213.

21 Zoja C, Donadelli R, Colleoni S, Figliuzzi M, Bonazzola S, Morigi M, Remuzzi G: Protein overload stimulates RANTES production by proximal tubular cells depending on NF-кB activation. Kidney Int 1998;53:1608-1615.

22 Umekawa T, Chegini N, Khan SR: Increased expression of monocyte chemoattractant protein-1 by renal epithelial cells in culture on exposure to calcium oxalate, phosphate and uric acid crystals. Nephrol Dial Transplant 2003; 18:664-669.

23 Anders HJ, Frink M, Linde Y, Banas B, Wornle $\mathrm{M}$, Cohen CD, Vielhauer V, Nelson PJ, Gröne HJ, Schlöndorff D: CC chemokine ligand 5/RANTES chemokine antagonists aggravate glomerulonephritis despite reduction of glomerular leukocyte infiltration. J Immunol 2003; 170:5658-5666.

24 Vielhauer V, Eis V, Schlondorff D, Anders HJ Identifying chemokines as therapeutic targets in renal disease: lessons from antagonist studies and knockout mice. Kidney Blood Press Res 2004;27: 226-238.

25 Haberstroh U, Pocock J, Gomez-Guerrero C, Helmchen U, Hamann A, Gutierrez-Ramos JC, Stahl RA, Thaiss F: Expression of the chemokines MCP-1/CCL2 and RANTES/CCL5 is differentially regulated by infiltrating inflammatory cells. Kidney Int 2002;62:1264-1276.

26 Anders HJ, Vielhauer V, Schlöndorff D: Current paradigms about chemokines as therapeutic targets. Nephrol Dial Transplant 2004; 19: 2948-2951.

27 Liu ZH, Chen SF, Zhou H, Chen HP, Li LS: Glomerular expression of C-C chemokines in different types of human crescentic glomerulonephritis. Nephrol Dial Transplant 2003;18: 1526-1534.

28 Cockwell P, Chakravorty SJ, Girdlestone J, Savage CO: Fractalkine expression in human renal inflammation. J Pathol 2002;196:8590.
29 Furuichi K, Wada T, Sakai N, Iwata Y, Yoshimoto K, Shimizu M, Kobayashi K, Takasawa K, Kida H, Takeda SI, Mukaida N, Matsushima K, Yokoyama H: Distinct expression of CCR 1 and CCR5 in glomerular and interstitial lesions of human glomerular diseases. Am J Nephrol 2000;20:291-299.

30 Anders HJ, Vielhauer V, Kretzler M, Cohen CD, Segerer S, Luckow B, Weller L, Grone HJ, Schlondorff D: Chemokine and chemokine receptor expression during initiation and resolution of immune complex glomerulonephritis. $\mathrm{J}$ Am Soc Nephrol 2001;12:919-931.

31 Akira S, Hemmi H: Recognition of pathogenassociated molecular patterns by TLR family. Immunol Lett 2003;85:85-95.

32 Anders HJ, Banas B, Linde Y, Weller L, Cohen CD, Kretzler M, Martin S, Vielhauer V, Schlöndorff D, Gröne HJ: Bacterial CpGDNA aggravates immune complex glomerulonephritis: role of TLR9-mediated expression of chemokines and chemokine receptors. J Am Soc Nephrol 2003; 14:317-326.

33 Onuffer JJ, Horuk R: Chemokines, chemokine receptors and small-molecule antagonists: recent developments. Trends Pharmacol Sci 2002;23:459-467.

34 Kaufmann A, Salentin R, Gemsa D, Sprenger $\mathrm{H}$ : Increase of CCR 1 and CCR5 expression and enhanced functional response to MIP- $1 \alpha$ during differentiation of human monocytes to macrophages. J Leukoc Biol 2001;69:248252.

35 Ninichuk V, Gross O, Reichel C, Khandoga A, Pawar RD, Ciubar R, Segerer S, Belemezova E, Radomska E, Luckow B, de Lema GP, Murphy PM, Gao JL, Henger A, Kretzler M, Horuk R, Weber M, Krombach F, Schlöndorff D, Anders HJ: Delayed chemokine receptor 1 blockade prolongs survival in collagen 4A3-deficient mice with Alport disease. J Am Soc Nephrol 2005; 16:977-985

36 Eis V, Luckow B, Vielhauer V, Siveke JT, Linde Y, Segerer S, De Lema GP, Cohen CD, Kretzler M, Mack M, Horuk R, Murphy PM, Gao JL, Hudkins KL, Alpers CE, Grone HJ, Schlondorff D, Anders HJ: Chemokine receptor CCR1 but not CCR5 mediates leukocyte recruitment and subsequent renal fibrosis after unilateral ureteral obstruction. J Am Soc Nephrol 2004; 15:337-347.

37 Anders HJ, Belemezova E, Eis V, Segerer S, Vielhauer V, Perez de Lema G, Kretzler M, Cohen CD, Frink M, Horuk R, Hudkins KL, Alpers CE, Mampaso F, Schlondorff D: Late onset of treatment with a chemokine receptor CCR1 antagonist prevents progression of lupus nephritis in MRL-Fas(lpr) mice. J Am Soc Nephrol 2004;5:1504-1513.

38 Horuk R, Shurey S, Ng HP, May K, Bauman JG, Islam I, Ghannam A, Buckman B, Wei GP, Xu W, Liang M, Rosser M, Dunning L, Hesselgesser J, Snider RM, Morrissey MM, Perez HD, Green C: CCR1-specific non-peptide antagonist: efficacy in a rabbit allograft rejection model. Immunol Lett 2001;76:193-201. 
39 Bedke J, Kiss E, Horuk R, Neplson PJ, Gröne $\mathrm{HJ}$ : Blockade of rat chemokine receptor CCR1 by $\mathrm{BX} 471$ reduces acute rejection and is able to reduce chronic allograft nephropathy. Kidney Blood Press Res 2004;5:290.

40 Vielhauer V, Anders HJ, Mack M, Cihak J, Strutz F, Stangassinger M, Luckow B, Grone HJ, Schlondorff D: Obstructive nephropathy in the mouse: Progressive fibrosis correlates with tubulointerstitial chemokine expression and accumulation of $\mathrm{CC}$ chemokine receptor 2 and 5 positive leukocytes. J Am Soc Nephrol 2001;12:1173-1187.

41 Anders HJ, Vielhauer V, Frink M, Linde Y, Cohen CD, Blattner SM, Kretzler M, Strutz F, Mack M, Grone HJ, Onuffer J, Horuk R, Nelson PJ, Schlondorff D: A chemokine receptor CCR-1 antagonist reduces renal fibrosis after unilateral ureter ligation. J Clin Invest 2002; 109:251-259.
42 Topham PS, Csizmadia V, Soler D, Hines D, Gerard CJ, Salant DJ, Hancock WW: Lack of chemokine receptor CCR1 enhances Th1 responses and glomerular injury during nephrotoxic nephritis. J Clin Invest 1999; 104:15491557.

43 Takaya K, Koya D, Isono M, Sugimoto T, Sugaya T, Kashiwagi A, Haneda M: Involvement of ERK pathway in albumin-induced MCP-1 expression in mouse proximal tubular cells. Am J Physiol Renal Physiol 2003;284:F1037F1045.

44 Vielhauer V, Berning E, Linde Y, Kretzler M, Strutz F, Horuk R, Grone HJ, Schlondorff D, Anders HJ: A CCR1 antagonist reduces interstitial nephritis and fibrosis, but not proteinuria and glomerular pathology in murine adriamycin nephropathy. Kidney Int 2004;66: 2264-2278.
45 Rodgers KD, Rao V, Meehan DT, Fager N, Gotwals P, Ryan ST, Koteliansky V, Nemori $\mathrm{R}$, Cosgrove D: Monocytes may promote myofibroblast accumulation and apoptosis in Alport renal fibrosis. Kidney Int 2003;63:13381355.

46 Allen TJ, Cooper ME, Lan HY: Use of genetic mouse models in the study of diabetic nephropathy. Curr Diab Rep 2004;4:435-440.

47 Bohle A, Wehrmann M, Bogenschutz O, Batz C, Muller CA, Muller GA: The pathogenesis of chronic renal failure in diabetic nephropathy. Investigation of 488 cases of diabetic glomerulosclerosis. Pathol Res Pract 1991;187:251259.

48 Chow F, Ozols E, Nikolic-Paterson DJ, Atkins $\mathrm{RC}$, Tesch GH: Macrophages in mouse type 2 diabetic nephropathy: correlation with diabetic state and progressive renal injury. Kidney Int 2004; 65:116-128. 